

\section{XVR Chat}

The future is finally here, and we get to experience it wholeheartedly, or so to speak. If you are ready to experience the usual chatting with the lovely cam girls on a whole new level, then I think that you are ready to check out xvr.chat. This is a site filled with lots of webcam shows. However, this time, you will get to enjoy all of these naughty webcams through the VR.

\section{Combining webcam shows and VR}

We all already know that webcam shows are incredibly hot since you get to see the beautiful chick do all kinds of dirty things right in front of you, right? Well, imagine being able to see everything through the actual VR device... now that is something I can definitely get behind. I mean, xvr.chat is a site that will deliver just that, and you are free to browse it as much as you want.

I have been waiting for somebody to combine the two, and finally, it has happened. I think that everyone will love this combination, since what is there not to love? You have everything you want in one place... realistic shows, with beauties who enjoy spreading joy with all their viewers, and you get to enjoy watching everything in VR. I mean... what else do you want?

Of course, for those who prefer the professional scenes, you are welcome to check out those kinds of scenes, since the net is filled with VR porn. I have a lot of those kinds of sites reviewed already, so take your time and check them out, and those who are looking for the raw, vulnerable beauty of the amateur girls who like to masturbate and perform live while you watch them with the VR device, are welcome to check out xvr.chat.

VR has been around for quite some time now, and I am sure we all know what the fuck this hype is all about, right? Well, feel free to browse and find whatever the fuck you are searching for, as you scroll through and explore xvr.chat. This site will give you a little bit of everything, and thus I know that you will enjoy everything they have to offer.

\section{Basic design, nothing special.}

When you see a site that is dedicated to something so futuristic, you expect it to look futuristic as well, right? Well, that is not really the case, since you have a site that really looks basic. I kind of expected some spunk here and there, something to make the site pop, but instead, I got whatever the heck this is. Basically, I am trying to say that their design needs some fucking work.

I also know that most of you probably do not give a shit about the design or anything like that, right? But, for those who give a shit, I am here to say that the site looks like they did not try much to make their website seem presentable. Oh well, at least what they have to offer is great, and that is what matters the most, right?

They kind of look like a strip club, if a strip-club was a sex cams website, and you will understand what I mean when you see the site yourself. I am not saying that their site is particularly shitty looking, but I guess for my expensive tastes, I guess they could have done much better. However, you have lots and lots of content, so I am sure that you will not be complaining about the design.

\section{Lots of great performers.}

Compared to other webcam sites, I know that Xvr.chat is a newer site, or so to speak; however, they have a lot of fine ass presented here, and I know that you are bound to find a beauty who suits your taste just perfectly. I mean, you have so many hotties here, of all shapes and sizes, that there is really no chance that you will not find a babe who perfectly suits your taste. 
For example, when I was scrolling through all the performers, I saw many different types of hotties; from a skinny girl with a petite build masturbating with her kinky toys to a fatty beauty who loves to suck on her big tits. There were also cuties who were open to some BDSM play, and of course, some of their viewers got the chance to narrate the whole show.

Of course, this all depends on your personal taste, but just by staring at the thumbnails, it is pretty evident that you will find a lot of hotties here. Now, not all of the hotties on the site were actually streaming in 3D, but a lot of them were. However, whether you find a hottie in $3 \mathrm{D}$ or $2 \mathrm{D}$, does it really matter? If you are here to get off, I think that you will be satisfied either way.

You will also be provided with the basic information about the beauties, and you should check that out before talking to a certain beauty. You can see how long they are streaming; how many people are watching, or the languages they speak. The information provided tends to vary from one beauty to the other, but it is usually quite useful.

\section{You need a VR headset.}

While I feel like this should have been obvious at the same time, I can understand ladyboy how some of you might be confused. Well, you obviously need the fucking VR device if you want to enjoy the VR shows... I mean, that should be obvious. Even without the VR device, you can watch the beauties hosting the VR shows, but the picture might be a tad bit distorted, for obvious reasons.

Keep in mind that the VR gadgets are not that expensive, or well, not all of them. Of course, if you want the ULTRA HD ones, and all that shit, you will have to pay a bit more. But let us not forget that you have the cheap cardboard version of the VR as well... So, I am pretty sure that almost anyone can afford to have the VR.

But, if you do not have the VR, you can still watch all of the shows. There are many girls who host their live cam shows without the VR experience, and many who prefer to give you that realistic masturbation. I guess, all that is left for you to do, is find a beauty who suits your taste and start fapping... I mean, what else did you expect?

\section{Not many shows online.}

Usually, when you open a certain webcam site, you will have a lot of chicks listed from the very beginning, and they are all online and ready for action. Here, the babes who are listed at the beginning, are not necessarily online, even if they are suggested. I checked them out, and more than half of them were offline, which is not really the issue.

However, there were never that many girls live at the same time, and that might be because the site overall is a bit newer than the other ones, but then again, they might just not be that popular overall. I am not really sure, but even with those numbers, I still enjoyed browsing through and finding the shit that made my dick hard, which was not difficult.

There are lots and lots of hot babes who were ready to please me, and of course, I have my own VR device, which is how I know that owning one is definitely worth it. Watching a beauty get naughty in front of you, while you have the VR headset on, gives a whole new experience, trust me. I am sure that you will love it as much as I fucking did.

\section{Conclusion.}

At the end of the day, I do think that xvr.chat is worth the visit. But of course, this depends on what the fuck you are into. There are also a lot of issues that could be corrected and a lot of stuff that could be added to make the overall experience so much better. With a couple of changes, xvr.chat has the potential to be one of the best webcam sites out there.

Oh well, take your time and explore. There is a lot that xvr.chat has to offer, and thus I am sure that you will find your perfect content sooner or later. It is free to look around and check out just what the hype is all about. It is suitable for those who have a VR device, but it could also be enjoyable for those who do not have it. 


$\underline{\text { chaturbate }} \underline{\text { livejasmin }} \underline{\text { myfreecams }} \underline{\text { stripchat }} \underline{\text { streamate }}$

$\underline{\text { cams }}$

skyprivate

$\underline{\text { xvr-chat }}$ camsoda

slutroulette

$\underline{\text { xlovecam }}$

$\underline{\text { xcams }}$

camversity

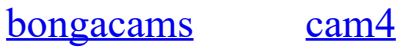

$\underline{\text { imlive }}$

$\underline{\text { flirt4free }}$

skipthegames $\quad$ celebjihad

yespornplease

$\underline{\text { wifelovers }}$

$\underline{\text { kindgirls }}$

$\underline{\text { swinglifestyle watchersweb }} \underline{\text { asstr }} \underline{\text { cliphunter }} \underline{\text { shooshtime }}$ 